\title{
Dental Caries and Related Factors in Vietnamese Dental Patients
}

\author{
Thoai Quoc Kieu ${ }^{1}$, Lan Thi Quynh Ngo², Thuy Anh Vu Pham* \\ ${ }^{1}$ 6th year dental student, Faculty of Odonto-Stomatology, University of Medicine and Pharmacy, Ho Chi Minh City, \\ 652 Nguyen Trai Str, District 5, Ho Chi Minh City, Vietnam \\ 2. Dean, Department of Dental Basic Science, Faculty of Odonto-Stomatology, University of Medicine and Pharmacy \\ Ho Chi Minh City, 652 Nguyen Trai Str, District 5, Ho Chi Minh City, Vietnam \\ 3. Lecturer, Department of Periodontology, Faculty of Odonto-Stomatology, University of Medicine and Pharmacy Ho \\ Chi Minh City, 652 Nguyen Trai Str, District 5, Ho Chi Minh City, Vietnam
}

*E-mail: pavthuy@hotmail.com

\begin{abstract}
Objective: To assess the association of dental caries with self-reported dental caries, dental knowledge and habit; and with obesity in Vietnamese dental patients

Methods: A cross sectional study was conducted on 367 adults (148 males, 219 females, mean age: 34.9 years old) who first visited at the Faculty of Odonto-Stomatology, University of Medicine and Pharmacy, Ho Chi Minh City, Vietnam. Self-reported dental caries, dental knowledge and habits, and anthropometric index were investigated by the selfadministered questionnaire. Dental status including DT, MT, FT were examined. The multiple logistic regression analysis was performed to explore factors that were associated with dental caries.

Results: Prevalence of dental caries in the study sample was $53.1 \%$. The factors significantly related to dental caries were subjects having dental scaling during last year $(\mathrm{OR}=2.1 ; \mathrm{CI}=1.1-4.0)$, self-checked teeth/gum frequency $(\mathrm{OR}=1.7$; $\mathrm{CI}=1.0-3.0)$, self-reported dental caries $(\mathrm{OR}=2.4 ; \mathrm{CI}=1.1-5.1)$, having knowledge on dental caries caused by bacteria $(\mathrm{OR}=2.1 ; \mathrm{CI}=1.1-4.0)$, having knowledge on regular dental checkups $(\mathrm{OR}=3.9 ; \mathrm{CI}=1.8-8.7)$ and overweight/obesity $(\mathrm{OR}=3.1 ; \mathrm{CI}=1.5-6.2)$.

Conclusion: Dental caries was associated with behavioral factors, dental knowledge and nutritional status in Vietnamese dental patients. Providing the dental knowledge with emphasis on oral self-checked oral disease behaviors and normal weight maintenance are necessary to prevent dental caries.
\end{abstract}

Keywords: dental caries, dental habit, dental knowledge, obesity, vietnam

\section{Introduction}

Oral diseases have put many obstacles to development of the country because they influence people's health, a country's economic potentials and development programs. Poor oral health impacts individuals in various ways. It can cause pain and affect quality of life, and accordingly reduce school and work productivity. ${ }^{1,2}$ Consequently, the requirements of dental healthcare services are costly and become a significant financial burden to both individuals and healthcare systems. ${ }^{3}$ The treatment of dental caries is expensive for governments not only of developing countries but also of developed countries and is around $5 \%$ to $10 \%$ of total health care expenditures in industrialized countries, exceeding the cost of treating cardiovascular diseases, cancer, and osteoporosis. ${ }^{4}$ FDI have called for global actions to reduce the burden of oral diseases. Particularly, the challenges of dental caries are significant concerns. ${ }^{1}$
According FDI, almost half (44\%) of the world population have been affected by tooth decay in 2010. Dental caries is the most widespread chronic disease worldwide and affects people of all ages during their life expectancy., Current data show that untreated decay of permanent teeth is the most prevalent condition out of 291 diseases. ${ }^{7}$ The levels of dental caries were low until recent years but prevalence rates of dental caries are now tending to increase rapidly in developing countries where sugar consumption is on the rise, lack of trained personnel, limited accessibility of oral health services and the health system are not able to provide appropriate prevention. ${ }^{5,8}$ Vietnam is a developing country with lower-middle income and suffering from the high level of tooth decay with more than 80 percent of adults having some decayed, missing or filled teeth. ${ }^{9}$ This may be due to socioeconomic, educational factors and people's awareness of the oral health. Dental caries usually progress invisibly, which causes patients to ignore the very first symptoms at 
early stages. ${ }^{1}$ Although dentist play a major role of clinically diagnosed dental needs, the patient's awareness of need for dental care is extremely important. As a consequence, the lack of awareness builds a barrier to utilization of heath care services that exacerbated dental caries prevalence and severity.

The caries process is now well-understood. Tooth decay results from interactions overtime between many host factors that include teeth and saliva, the bacterial biofilm and the presence of sugars from food. ${ }^{6,10}$ Like other oral diseases, dental caries share a wide range of risk factors and social determinants. ${ }^{1}$ The relationship between caries and personal lifestyle, behavioral factors have been detected through a substantial number of recent international studies. ${ }^{6,11,12}$ Other risk factors related tocaries include poverty, social status, level of education and dental insurance coverage. 6 In addition, a systematic review was conducted by Kantovitz et $a l^{13}$ indicated a positive relationship between obesity and periodontal disease. Although the problem of identifying potentially related factors and predictors of dental caries has received considerable attention in the scientific literature, ${ }^{14}$ little is known about dental caries and correlated factors in Vietnamese dental patients who are specific subjects with high dental needs and often have greater overall oral health problems. ${ }^{15}$ This is maybe due to the fact that most patients visit dental clinics at the later stages of dental diseases with severe symptoms that patients may report. The purpose of this study was to investigate the relationship of dental caries with dental habits, selfreported oral diseases, dental knowledge and body max index among patients who first visited The Faculty of Odonto-Stomatology, University of Medicine and Pharmacy, Ho Chi Minh city, Vietnam.

\section{Materials and Methods}

\section{Subjects}

A cross-sectional study conducting on convenience sample including 367 adult patients (mean age $34.9 \pm 13.5$ ) who first visited the 3rd Out Patient Section, Faculty of Odonto-Stomatology of the University of Medicine and Pharmacy, Ho Chi Minh city, Vietnam in 2013-2014. Subjects who suffered from systemic diseases such as diabetes, cancer, chronic kidney diseases ...were excluded. All participants were informed both verbally and in writing about the purposes and procedures of the study before they signed a consent form. Ethical clearance for this study was approved by the Ethical Review Committee of the University of Medicine and Pharmacy, Ho Chi Minh City.

\section{Questionnaire}

A self-administered questionnaire was administered prior to the dental examination. All items of this questionnaire were explained clearly to the participants. The information on the questionnaire contains variables such as sociodemographic information, dental knowledge, dental behaviors, self-perception of oral health and anthropometric data:
Sociodemographic information: Name, age, gender.

Dental behaviors: frequency of dental visit, dental scaling during last previous 12 months; self-check-up gum/teeth behaviors; frequency of tooth brushing and tongue brushing behavior.

Dental knowledge: A concept of questions were proposed to assess the level of dental knowledge of the subject about: receiving oral hygiene instruction by professional; importance on regularly dental visit; having knowledge on dental caries caused by bacteria; having knowledge on dental caries can be prevented.

Self-perception of oral health: presence of dental caries, clean teeth/mouth and presence of calculus.

Anthropometric indices: height and weight. Body max index (BMI) was calculated from weight in kilograms divided by square height in meters.

\section{Oral examination}

All subjects underwent a standard oral examination. Dental caries was evaluated clinically by a team of trained students and one dentist. Clinical assessment of dental caries was done by employing the decayed missed filled teeth (DMFT index) which was recorded in all teeth with help of dental mirror, explorer and light.

\section{Statistical analysis}

The Chi-square test was used to test the association between dental caries and each independent variable including socio-demographic characteristics, dental behaviors, dental knowledge, self-perception of oral health and BMI. Statistical significance was determined at $p=0.05$. Variables which showed statistically significant associations with dental caries in the Chi-square test were entered into the multiple logistic regression analysis as independent variables and using dental caries $(0=$ "no decayed tooth" and 1 = "having at least 1 decayed tooth") as the dependent variable for further investigate the degree of association. Crude (unadjusted) odds ratios (OR) and their $95 \%$ confidence intervals (CI) were calculated for each independent variable. Statistical analyses were carried out using the SPSS 17.0 software.

\section{Results}

\section{Socio-demographic characteristics}

In this study, a total of 367 patients (mean age of $34.9 \pm 13.5$ years) comprised of $40.3 \%$ males and $59.7 \%$ females. Participants had age range from 18 to above, including 207 subjects from 18 to 35 years old and 160 subjects from 35 years old or older.

\section{Oral health knowledge, self-perception of oral health and behavioral characteristics}

About $55 \%$ of total sample (199 patients) confirmed that they were professionally received how to brush their teeth by dentists or dental nurses in the last previous year. The necessary of routine dental check were reported by 324 
subjects $(88.3 \%)$. About $76.3 \%$ of patients answered that they "knew" that dental caries caused by bacteria. Almost $80 \%$ of subjects $(79.6 \%)$ were in agreement that dental caries can be prevented.

Approximately $52 \%$ and nearly $26 \%$ of subjects reported that they made a dental visit and visited dentists for dental scaling during the last year, respectively. Only 98 subjects (26.7\%) checked their teeth/gum regularly. The majority of the subjects answered that they brushed their teeth at least once daily, however only one-third of study subjects brushed their teeth 3 times daily or more. Brushing tongue frequently was informed by $49 \%$ of the participants. Almost $85 \%$ of the subjects were non-smoker while only 55 out of 367 subjects were current or past smokers.

Most participants assessed their oral hygiene as good $(\mathrm{n}=$ 209 to $56,9 \%$ ). In study population, $85.3 \%$ of subjects reported their perception of presence tooth decay, $56.9 \%$ of subjects noticed their teeth and mouth clean and the perception of presence dental calculus was confirmed in $91.8 \%$ of responders.

\section{Dental caries status}

Prevalence of dental caries in the sample was $53.1 \%$. All subjects were dentate ( 7 to 28 teeth with mean number of

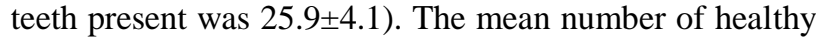
teeth was $21.7 \pm 5.8$, while mean numbers of decay teeth, filled teeth and missing teeth were $2.4 \pm 2.1,1.9 \pm 3.4$ and $2.1 \pm 4.1$, respectively. 221 patients $(60.2 \%)$ out of study population had at least one decayed.

\section{Relationship between socio-demographic, behavioral characteristics and dental caries}

The association between socio-demographic, behavioral characteristics and dental caries were given in table 1 . There was no statistically significant relationship between age, tongue brushing habit and dental caries. Chi-square analyses showed significantly higher percentages of males have dental caries than females. Patients who not made a dental visit during last previous 12 months had significantly higher proportion of dental caries $(66.1 \%)$ compared with the routine attendees $(\mathrm{p}=0.033)$. The prevalence of dental caries was statistically significant lower among the subjects who had visited dentists for scaling within the past 12 months or had checked their teeth/gum in mirror frequently than their counterpart ( $\mathrm{p} \leq$ 0.001). The subjects who brushed their teeth at least 3 times daily had significantly lower prevalence of dental caries compared with those who have lower frequency of tooth brushing. Current cigarette smoking was found to be significantly very highly positively correlated with prevalence of dental caries among study sample ( $\mathrm{p}<$ 0.001).

Relationship between self-perception of oral health, dental knowledge and dental caries
Table 2 indicated the relationship between self-perception of oral health, dental knowledge and dental caries. Patient's perception of decayed tooth and their oral hygiene status as "clean" was found to be significantly negatively correlated with dental caries $(\mathrm{p}<0.01)$.

Patients who reported their perception of presence dental calculus had significantly higher percentages of tooth decayed than those with no noticed of dental calculus but not reached statistical significance $(\mathrm{p}=0.7)$.

Subjects were guided how to brush their teeth by professionals within the past year had significantly lower dental caries prevalence compared with subjects had not received oral hygiene instruction $(\mathrm{p}<0.05)$. In addition, Prevalence of dental caries was significant lower among subjects reported that they "knew" that dental caries caused by bacteria and dental caries can be prevented than their counterpart $(\mathrm{p}<0.05)$. There was not significantly associated between the knowledge about "should make a dental visit routinely" and dental caries proportion.

\section{Relationship between nutritional status and dental caries}

Figure.1 indicated the relationship between nutritional status and dental caries. There was statistically significant difference in prevalence of dental caries between different body max index groups. An upward trend of dental caries prevalence between different body max index groups was observed when the prevalence of dental caries was $50.8 \%$, $55.6 \%$ and $80.2 \%$ of under weigh group, normal weigh group and overweigh/obesity group, respectively.

\section{Multivariate analysis of dental caries with different factors}

To build the multivariate model, all variables included socio-demographic characteristics, dental behaviors, selfperception of oral health, dental knowledge and arthropometric characteristics were entered, and those with $\mathrm{p} \geq 0.05$ were removed one by one from the model.

Table 3 showed multivariate logistic regression analysis of dental caries with potential factors. Subjects who did not scaling dental calculus within the past 12 months (OR $=2.06, \mathrm{p}=0.026$ ) were more likely to have dental caries than subjects had dental scaling with the same time period. Further, subjects who did not frequently check their teeth/gum by mirror $(\mathrm{OR}=1.76, \mathrm{p}=0.04)$, had no knowledge about dental caries were caused by bacteria $(\mathrm{OR}=1.93, \mathrm{p}=0.037)$, did not perceive presence dental caries $(\mathrm{OR}=2.75, \mathrm{p}=0.006)$, perceived clean teeth/mouth $(\mathrm{OR}=1.76, \mathrm{p}=0.024)$ were more likely to have dental carries compared with their counterpart. Overweight or obese subjects were more likely than normal weigh and under weigh subjects to have dental caries with odds ratio of $2.31(95 \% \mathrm{Cl} 1$. 
UIP HEALTH MED., 2016, 1(1)

doi: http://dx.doi.org/10.7454/uiphm.v1i0.46

Table 1. Relationship between sociodemographic, behavioral characteristics and dental caries, Periodontal disease

\begin{tabular}{|c|c|c|c|c|}
\hline \multirow[t]{2}{*}{ Variable } & \multicolumn{2}{|c|}{ Dental caries, $n(\%)$} & \multirow{2}{*}{$\mathbf{p}$} & \multirow[t]{2}{*}{ Total, n (\%) } \\
\hline & No & Yes & & \\
\hline \multicolumn{5}{|l|}{ Age } \\
\hline $18-35$ & $81(39.1)$ & $126(60.9 \%)$ & 0.83 & $207(100 \%)$ \\
\hline$>35$ & $65(40.6)$ & $95(59.4 \%)$ & & $160(100 \%)$ \\
\hline \multicolumn{5}{|l|}{ Gender } \\
\hline Male & $49(33.1 \%)$ & $99(66.9 \%)$ & 0.039 & $148(100 \%)$ \\
\hline Female & $97(44.3 \%)$ & $122(55.7 \%)$ & & $219(100 \%)$ \\
\hline \multicolumn{5}{|c|}{$\begin{array}{l}\text { Dental check-ups within } \\
\text { the past year }\end{array}$} \\
\hline Yes & $86(45.3 \%)$ & $104(54.7 \%)$ & 0.033 & $190(100 \%)$ \\
\hline No & $60(33.9 \%)$ & $117(66.1 \%)$ & & $177(100 \%)$ \\
\hline
\end{tabular}

Dental scaling within the past year

\begin{tabular}{|c|c|c|c|c|}
\hline Yes & $56(58.9 \%)$ & $39(41.1 \%)$ & $<0.001$ & $95(100 \%)$ \\
\hline No & $90(33.1 \%)$ & $182(66.9 \%)$ & & $272(100 \%)$ \\
\hline \multicolumn{5}{|l|}{$\begin{array}{l}\text { Frequency of self- } \\
\text { checking teeth/gum }\end{array}$} \\
\hline Frequently/ weekly & $54(55.1 \%)$ & $44(44.9 \%)$ & $<0.001$ & $98(100 \%)$ \\
\hline Never/ occasionally & $92(34.2 \%)$ & $171(65.8 \%)$ & & $269(100 \%)$ \\
\hline \multicolumn{5}{|l|}{$\begin{array}{c}\text { Frequency of tongue } \\
\text { brushing }\end{array}$} \\
\hline Frequently/ weekly & $69(31.0 \%)$ & $111(61.7 \%)$ & 0.255 & $180(100 \%)$ \\
\hline Never/ occasionally & $77(41.2 \%)$ & $110(58.8 \%)$ & & $187(100 \%)$ \\
\hline \multicolumn{5}{|l|}{$\begin{array}{l}\text { Frequency of tooth } \\
\text { brushing }\end{array}$} \\
\hline $1-2$ times/ day & $99(35.9 \%)$ & $177(64.1 \%)$ & 0.009 & $276(100 \%)$ \\
\hline$\geq 3$ times/ day & $47(51.6 \%)$ & $44(48.4 \%)$ & & $91(100 \%)$ \\
\hline \multicolumn{5}{|l|}{ Smoking } \\
\hline $\begin{array}{l}\text { Non-smokers/ Fomer } \\
\text { smokers }\end{array}$ & $\begin{array}{c}138 \\
(43.8 \%)\end{array}$ & $177(56.2 \%)$ & $<0.001$ & $315(100 \%)$ \\
\hline Current smoker & $8(15.4 \%)$ & $44(84.6 \%)$ & & $52(100 \%)$ \\
\hline
\end{tabular}

The P-value was calculated using the Chi-Square test. Statistical significant difference with $p<0.05$. 
UIP HEALTH MED., 2016, 1(1)

doi: http://dx.doi.org/10.7454/uiphm.v1i0.46

Table 2. Relationship between self-perception oral health and dental knowledge with dental caries

\begin{tabular}{l|c|c|c|c}
\hline Variables & \multicolumn{2}{|c|}{ Dental caries; n (\%) } & \multicolumn{1}{c|}{$\begin{array}{c}\text { Total } \\
\text { n }(\%)\end{array}$} & Yes \\
\cline { 2 - 3 } & & No & & \\
\hline
\end{tabular}

Presence of caries

\begin{tabular}{|c|c|c|c|c|}
\hline Yes & $36(66.7)$ & $18(33.3 \%)$ & $54(100 \%)$ & $<0.001$ \\
\hline No & $110(35.1)$ & $203(64.9 \%)$ & $313(100 \%)$ & \\
\hline \multicolumn{5}{|c|}{ Cleanness of teeth/mouth } \\
\hline Yes & $70(33.5 \%)$ & $139(66.5 \%)$ & $209(100 \%)$ & 0.005 \\
\hline No & $76(48.1 \%)$ & $82(51.9 \%)$ & $158(100 \%)$ & \\
\hline \multicolumn{5}{|c|}{ Presence of dental calculus } \\
\hline Yes & $133(39.5 \%)$ & $204(60.5 \%)$ & $337(100 \%)$ & 0.70 \\
\hline No & $13(43.3 \%)$ & $17(56.7 \%)$ & $30(100 \%)$ & \\
\hline
\end{tabular}

Dental knowledge

Receiving instructions on oral hygiene by professionals

\begin{tabular}{ccccc}
\hline Yes & $91(45.7 \%)$ & $108(54.3 \%)$ & $199(100 \%)$ & 0.014 \\
No & $55(32.7 \%)$ & $113(67.3 \%)$ & $168(100 \%)$ \\
\hline
\end{tabular}

Visiting a dentist regularly is essential for oral health

\begin{tabular}{ccccc}
\hline Yes & $131(40.4 \%)$ & $193(59.6 \%)$ & $324(100 \%)$ & 0.512 \\
No & $15(34.9 \%)$ & $28(65.1 \%)$ & $43(100 \%)$ & \\
\hline
\end{tabular}

Bacteria are responsible for dental caries

\begin{tabular}{|c|c|c|c|c|}
\hline Yes & $123(43.9 \%)$ & $157(56.1 \%)$ & $280(100 \%)$ & 0.004 \\
\hline No & $23(26.4 \%)$ & $64(73.6 \%)$ & $87(100 \%)$ & \\
\hline \multicolumn{5}{|c|}{ Dental caries can be prevented } \\
\hline Yes & $90(33.1 \%)$ & $182(66.9 \%)$ & $272(100 \%)$ & $<0.001$ \\
\hline No & $56(58.9 \%)$ & $39(41.1 \%)$ & $95(100 \%)$ & \\
\hline
\end{tabular}

The p-value was calculated using the Chi-Square test. Significant difference for $p<0.05$ 
UIP HEALTH MED., 2016, 1(1)

doi: http://dx.doi.org/10.7454/uiphm.v1i0.46

Table 3. Multivariate analysis of dental caries with different factors

\begin{tabular}{|c|c|c|c|c|}
\hline Variables & n $(\%)$ & OR & Cl $95 \%$ & p \\
\hline \multicolumn{5}{|l|}{$\begin{array}{l}\text { Dental scaling within } \\
\text { the past year }\end{array}$} \\
\hline Yes & $95(25.9 \%)$ & 1 & & \\
\hline No & $272(74.1 \%)$ & 2.20 & $\begin{array}{l}1.23- \\
3.94\end{array}$ & 0.008 \\
\hline \multicolumn{5}{|l|}{ Smoking } \\
\hline \multicolumn{5}{|l|}{ Non-smokers /pastsmokers } \\
\hline & $315(85.8 \%)$ & 1 & & \\
\hline Current smokers & $52(14.2 \%)$ & 2.47 & $\begin{array}{l}1.22- \\
4.99\end{array}$ & 0.012 \\
\hline \multicolumn{5}{|l|}{$\begin{array}{l}\text { Receiving instructions on oral } \\
\text { hygiene by professionals }\end{array}$} \\
\hline Yes & $199(54.2 \%)$ & 1 & & \\
\hline No & $168(45.8 \%)$ & 1.73 & $\begin{array}{l}1.05- \\
2.86 \\
\end{array}$ & 0.031 \\
\hline \multicolumn{5}{|l|}{ BMI } \\
\hline Underweigh /Normal weigh & $286(77.9 \%)$ & 1 & & \\
\hline $\begin{array}{l}\text { Over weigh } \\
\text { /Obesity }\end{array}$ & $81(22.1 \%)$ & 4.78 & $\begin{array}{l}2.61- \\
8.74\end{array}$ & $<0.001$ \\
\hline
\end{tabular}

OR: odds ratio; Cl: confidence intervals; Significant difference for $p<0.05$

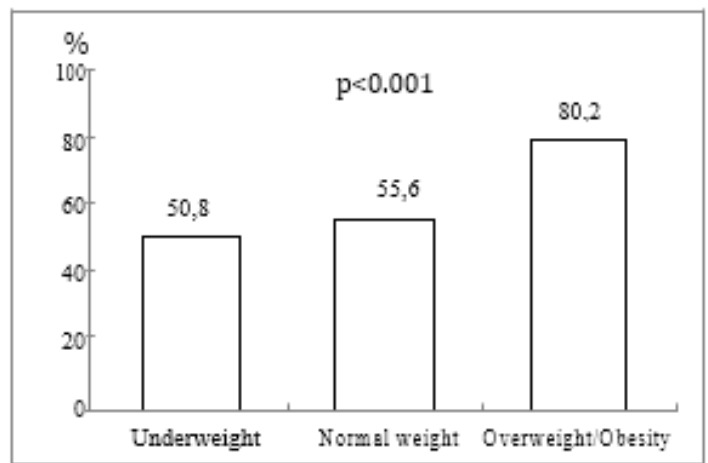

Figure 1. Prevalence of dental caries by nutritional status

\section{Discussion}

A cross sectional study was conducted on 367 adult patients (148 males, 219 females, mean age: 34.9) who first visited the Faculty of Odonto-Stomatology, University of Medicine and Pharmacy, Ho Chi Minh City in 2014. Multinomial logistic regression model was used to evaluate the association between dental caries and potential risk factors including dental habits, self-reported oral diseases, dental knowledge and nutrition status.

A study on New Zealand adults found that routine attendees who usually visited for a check-up and made a dental visit during the previous 12 months had better oral health outcomes. ${ }^{16}$ Results from our multivariate analysis showed that patients who have not visited dental clinic for the last year were more likely to have dental caries $(\mathrm{OR}=$ $2.06, \mathrm{p}=0.026$ ) in comparison with their counterparts. At our Faculty, before scaling calculus and dental plaque, dental major students had the responsibility of teaching patients appropriate oral hygiene strategies to maintain oral health. This may, of course, be that patients are more likely to pay attention to the role of oral health and associated oral health messages influencing their self-care behavior. Despite the fact that promoting regular dental visits is one of cornerstones of preventive dentistry (Alexsson et al, 1991; Murray, 1996; Richards and Ameen, 2002), ${ }^{16}$ in our study only one-fourth of the subjects $(25.9 \%)$ made a dental visit during previous 12 months. This rate is quite low compared with that of Western countries with $50 \%$ of the population making a 
dental visit on a regular basis and much lower than that of the U.S $(62 \%) .{ }^{17,18}$ Several studies indicated that regular dental visit behavior was significantly associated with socio-demographic factors such as age, sex, educational level and household income. ${ }^{19,20}$ In Vietnam, little is known about the relationship between hindered factors to access oral healthcare and routine attendees; and we, therefore, need further research which then indicates measures to promote regular dental visit behavior among Vietnamese population.

An important task of oral health professionals is to instill in their patients correct oral habit to prevent oral diseases. The first step in establishing a habit is to provide relevant knowledge to patients and to raise their awareness of how to prevent oral diseases. ${ }^{21}$ Results of our study indicate that a large number of patients have good level of dental knowledge. Over $74 \%$ of the subjects known that dental caries can be prevented. In addition, over $76 \%$ patients answered that they know that tooth decay caused by bacteria. Our study showed that dental knowledge was significantly associated with dental caries. For example, the participants who had been recognized the role of bacteria in the oral microflora as the main cause of caries were less likely to have tooth decay than those do not know that $(\mathrm{OR}=1.93, \mathrm{p}=0.009)$. At our faculty, Bass technique and modified Bass (Mod-Bass) technique have been proposed as two of most commonly recommended tooth-brushing methods in dental practice. The introduction of specific tooth-brushing method significantly improved the level of oral hygiene which affect positively to oral health status. ${ }^{22}$ This finding, in agreement with previous studies suggests that dental knowledge statistically significant relates to oral health status and may influence oral health attitudes and behaviors. ${ }^{23,24}$ This suggests that more community-based oral health education programs should be planned and conducted to improve their oral health knowledge. It also emphasizes the need for further dental health education and indicates the key role of professionals in providing proper dental knowledge to patients.

Our study demonstrated the wide discrepancy between the self-perception of the subject and the oral health condition observed by the professional. The participant who perceived that their oral health in a good state with no symptoms of presence dental caries more likely to have tooth decay $(\mathrm{OR}=2.75 ; 95 \% \mathrm{Cl} 1.33$ to 5.68$)$. It can be explained that although clinical measures are reliable and valid measures of oral health condition, dental diseases are manifested along a continuum of severity such that patients may be unaware of these conditions at the early state1. In addition, although patients may aware evidence of dental disease, there may be no related symptoms. The perception of individuals about their oral health may be related to clinical conditions as well as socioeconomic and behavioral conditions, such as dental pain, family income, educational level, and even visits to the dentist. ${ }^{25,26}$ In a developing country like Vietnam, with limited resources, closing the discrepancy between self-perceived need for dental care and clinically diagnosed dental problems play a key role to reduce the burden of dental caries. As an effectiveness measure, health education with the aim to provide adequate dental knowledge to dental patients should be encouraged. It would be possible to improve individuals' capacity to carry out oral self-examination and to identify non-painful signs and symptoms of oral diseases at an earlier stage, and to correlate these with the need for dental treatment.

Diet plays an important role in the increased prevalence of obesity due to the increased consumption of excess calories from fats and added sugars in foods. Although the relationship between obesity and dental caries is unclear, the presence of a common factor such as a high-sugar diet seems to be the most acceptable theory to explain the association between obesity and dental caries. 27,28,29 Our study showed that group of overweigh and obesity were 2.31 times $(\mathrm{OR}=2.31 .95 \% \mathrm{Cl} 1.02$ to 4.43$)$ more likely to have dental caries to compare with group of underweight and normal weight. The age-standardized prevalence of overweight and obesity among Vietnamese adults in Ho Chi Minh City was 26.2 percent and 6.4 percent, respectively (using the Asian-specific BMI cutoff values) ${ }^{30}$ This prevalence tends to be increased with the improvement of economic situation. Therefore, to reduce the prevalence of dental caries, preventing obesity should be emphasized. Despite the fact that several methods have been proposed for weight loss in obese patients including dieting and physical activity, pharmacologic treatment and surgical intervention, ${ }^{31,32,33}$ advising lifestyle changes and prescribing balanced diet to control body weight seem to be effective and economical measures. Dentist should provide their obese patients about the risk of dental caries and underline the importance of maintaining good oral health.

This study has certain limitations. Because we used a convenient sample of recruited patients in the dental hospital, the sample was not representative of general population in Vietnam. Future studies should be conducted with a randomly drawn sample at a population level. Furthermore, this is a cross sectional analysis in which only the relationship between dental caries and various presumptive risk factors can be assessed. Future investigation in a longitudinal study will be required to clarify the true risk factors in this study group. However, in spite of these limitations, this study provides valuable information on a Vietnamese population group which had not been previously subjected to such investigations.

\section{Conclusions}

In conclusion, dental caries associated with behavioral factors, dental knowledge and nutritional status in patients reporting at the Faculty of Odonto-Stomatology, University of Medicine and Pharmacy, Ho Chi Minh City. Providing the dental knowledge with emphasis on oral self-checked oral disease behaviors and normal weight maintenance are necessary to prevent dental caries. 


\section{References}

1. Fédération Dentaire Internationale. Oral Health Atlas : The Challenge Of Oral Disease - A Call For Global Action. (2nd ed.). Bangkok: Annual World Dental Congress; 2015.

2. Paulo Floriani Kramer, Carlos Alberto Feldens,Simone Helena Ferreira, Juliane Bervian, Priscila Humbert Rodrigues, Marco Aurélio Peres. Exploring the impact of oral diseases and disorders on quality of life of preschool children. CommunityDent Oral Epidemiol. 2013; 41(4): 327-35.

3. Yee R, Sheiham A. The burden of restorative dental treatment for children in third world countries. IntDent $\mathbf{J}$. 2002;52:1-9.

4. Paula Moynihan and Poul Erik Petersen. Diet, nutrition and the prevention of dental diseases. Public Health Nutr. 2004;7(1A):201-26.

5. Poul Erik Petersen, Denis Bourgeois, Hiroshi Ogawa, Saskia Estupinan-Day, and Charlotte Ndiaye. The global burden of oral diseases and risks to oral health. Bull World Health Organ. 2005;83(9):661-9.

6. Robert H Selwitz, Amid I Ismail, Nigel B Pitts. Dental caries. Lancet. 2007; 369(9555):51-9.

7. W. Marcenes, N.J. Kassebaum, E. Bernabé, A. Flaxman, M. Naghavi , A. Lopez, and C.J.L.Murray. Global Burden of Oral Conditions in 1990-2010-A Systematic Analysis. J Dent Res. 2013;92(7):592-7.

8. Manji, O Fejerskov. Dental Caries in Developing Countries in Relation to the Appropriate Use of Fluoride. J Dent Res. 1990;69(2):733-41.

9. Loc Giang Do,Andrew John Spencer,Kaye Frances Roberts-Thomson,Hai Dinh Trinh, and Thuy Thanh Nguyen. Oral Health Status of Vietnamese Adults: Findings From the National Oral Health Survey of Vietnam. Asia Pac J Public Health. 2011;23(2):228-36.

10. John D.B Featherstone. The science and practice of caries prevention. J Am Dent Assoc. 2000;131(7):887-99.

11. Featherstone JD, Adair SM, Anderson MH, et al. Caries management by risk assessment: consensus statement, April 2002. J Calif Dent Assoc. 2003:31(3): 257-69.

12. Anderson M. Risk assessment and epidemiology of dental caries:review of the literature. Pediatr Dent. 2002;24(5):377-85.

13. Kantovitz KR, Pascon FM, Rontani RMP, Gavião MBD. Obesity and dental caries - a systematic review. Health Prev Dent. 2006;4(2):137-44.

14. Mario T, Maurizio B, Denise C, Gaetano I, Valeria L, Matteo S, Antonella P. Assessing Risk Factors for Dental Caries: A Statistical Modeling Approach. Caries Res. 2015;49(3):226-35.

15. Pham TA, Ueno M, Shinada K, Yanagisawa T, Wright FA, Kawaguchi Y. Periodontal disease and related factors in Vietnamese dental patients. Oral Health Prev Dent. 2011;9(2):185-94.

16. Thomson WM, Williams, Broadbent, Poulton R, and Locker D. Long-term Dental Visiting Patterns and Adult Oral Health. J Dent Res. 2010;89(3):307- 11.

17. Jamieson LM, Thomson M. Dental health, dental neglect, and use of services in an adult Dunedin population sample. N Z Dent J. 2002;98(431):4-8.

18. U.S Department of Health and Human Services. Health, United States, 2015 -With Speccial Feature on Racial and
Ethnic Health Disparities. DHHSPublication. 2016; Table 78:270.

19. Kiyak HA, Reichmuth M. Barriers to and enablers of older adults' use of dental services. J DentEduc.2005;69(9):97586.

20. Lu Liu, Ying Zhang, Wei Wu, Ruibo Cheng. Characteristics of dental care-seeking behavior and related sociodemographic factors in a middle-aged and elderly population in northeast China. BMC Oral Health. 2015;15(1):66

21. Vangipuram S, Rekha R, Radha G, Pallavi S K. Assessment of oral health attitudes and behavior among undergraduate dental students using Hiroshima University Dental Behavioral Inventory HU-DBI. J Indian Assoc Public Health Dent. 2015;13(1):52-7

22. M Poyato-Ferrera,JJ Segura-Egea,P Bullón-Fernández. Comparison of modified Bass technique with normal toothbrushing practices for efficacy in supragingival plaque removal. Int J Dent Hyg. 2003 May;1(2):110-4.

23. MohammadAbdul Baseer, Mohammed Suliman Alenazy, MohammadAlAsqah, Mansoor Al Gabbani, AleemullahMehkari. Oral health knowledge, attitude and practices among health professionals in King Fahad Medical City, Riyadh. Dent Res J (Isfahan). 2012;9(4):386-92.

24. Lin HC, Wong MC, Wang ZJ, Lo EC. Oral health knowledge, attitudes, and practices of Chinese adults. J Dent Res.2001;80(5):1466-70.

25. Mesas, A. E., De Andrade, S. M. and Cabrera, M. A. S. (2008), Factors associated with negative self-perception of oral health among elderly people in a Brazilian community. Gerodontology. 2008;25(1):49-56.

26. Heft, M. W., Gilbert, G. H., Shelton, B. J. and Duncan, R. P. Relationship of dental status, sociodemographic status, and oral symptoms to perceived need for dental care. Community Dent Oral Epidemiol. 2003;31(5):351-60.

27. Hooley M, Skouteris H, Boganin C, Satur J, Kilpatrick N. Body mass index and dental caries in children and adolescents: a systematic review of literaturepublished 2004 to 2011. Syst Rev. 2012;1:57.

28. Kantovitz KR, Pascon FM, Rontani RM, GaviãoMB Obesity and dental caries--A systematic review. Oral Health Prev Dent. 2006;4(2):137-44.

29. Silva AE, Menezes AM, Demarco FF, Vargas-Ferreira F, Peres MA. Obesity and dental caries: systematic review. Rev Saude Publica.2013;47(4):799-812.

30. Cuong TQ, Dibley MJ, Bowe S, Hanh TT, Loan TT. Obesity in adults: an emerging problem in urban areas of Ho Chi Minh City, Vietnam. Eur JClin Nutr. 2007;61(5):67381.

31. Vesely JM, DeMattia LG. Obesity: dietary and lifestyle management. FP Essent. 2014;425:11-5.

32. Sarah R. Erlanger, PharmD and Emily A. Henson, PharmD. Classification and Pharmacological Management of Obesity. P T. 2008;33(12):724-28.

33. American College of Cardiology/American Heart Association Task Force on Practice

Guidelines, Obesity Expert Panel, 2013..Expert

PanelReport: Guidelines (2013) for the management of overweight and obesity in adults.Obesity (Silver Spring).2014;22 （2):S41-410 